\title{
Catechin-based extract optimization obtained from Arbutus unedo L. fruits using maceration/microwave/ultrasound extraction techniques
}

\author{
Bianca R. Albuquerque ${ }^{\mathrm{a}, \mathrm{b}}$, Prieto M.A. ${ }^{\mathrm{c}}$, Maria Filomena Barreiro ${ }^{\mathrm{d}}$, Alírio Rodrigues ${ }^{\mathrm{e}}$, \\ Thomas P. Curran ${ }^{\mathrm{f}}$, Lillian Barros ${ }^{\mathrm{a}, \mathrm{d}}$, Isabel C.F.R. Ferreira ${ }^{\mathrm{a}, *}$ \\ a Centro de Investigação de Montanha (CIMO), ESA, Instituto Politécnico de Bragança, Campus de Santa Apolónia, 1172, $5300-253$ Bragança, Portugal \\ b Departamento de Alimentos, Universidade Tecnológica Federal do Paraná - Campus de Medianeira, Avenida Brasil, 4232 CEP 85884-000, Caixa Postal \\ 271, Medianeira, Brasil, Brazil \\ ${ }^{c}$ Nutrition and Bromatology Group, Faculty of Food Science and Technology, University of Vigo, Ourense Campus, E32004 Ourense, Spain \\ ${ }^{\mathrm{d}}$ Laboratory of Separation and Reaction Engineering - Laboratory of Catalysis and Materials (LSRE-LCM), Polytechnic Institute of Bragança, Campus de \\ Santa Apolónia, 1134, 5301-857 Bragança, Portugal \\ ${ }^{\mathrm{e}}$ Laboratory of Separation and Reaction Engineering (LSRE) - Associate Laboratory LSRE/LCM, Faculty of Engineering, University of Porto, Porto, Portugal \\ ${ }^{\mathrm{f}}$ UCD School of Biosystems and Food Engineering, University College Dublin, Belfield, Dublin 4, Ireland
}

\section{A R T I C L E I N F O}

\section{Article history:}

Received 31 August 2016

Received in revised form 4 October 2016

Accepted 27 October 2016

Available online 5 November 2016

\section{Keywords:}

Arbutus unedo L. fruits

Catechin

Valorisation

Maceration/microwave/ultrasound assisted

extraction

Response surface methodology

\begin{abstract}
A B S T R A C T
This study compares three extraction techniques (maceration, microwave and ultrasound) for catechin recover from Arbutus unedo fruit extracts. To obtain the conditions that maximize catechin extraction yield, a response surface methodology was applied using a 3-level full factorial Box-Behnken design in which the processing time $(t)$, temperature $(T)$, ultrasonic power $(W)$ and ethanol percentage (Et\%) were the relevant independent variables with the response (catechin content, $\mathrm{mg} / \mathrm{g} \mathrm{dw}$ ) measured by HPLC-PDA. A fixed solid/solvent ratio of $50 \mathrm{~g} / \mathrm{L}$ was used in all techniques. Maceration and microwave extractions were found to be the most effective methods, capable of yielding $1.38 \pm 0.1$ and $1.70 \pm 0.3 \mathrm{mg} / \mathrm{g} \mathrm{dw}$ of catechin, respectively at the optimal extraction conditions. The optimal conditions for maceration were $93.2 \pm 3.7 \mathrm{~min}, 79.6 \pm 5.2{ }^{\circ} \mathrm{C}$ and $23.1 \pm 3.7 \%$ of ethanol, while for the microwave extraction were $42.2 \pm 4.1 \mathrm{~min}, 137.1 \pm 8.1^{\circ} \mathrm{C}$ and $12.1 \pm 1.1 \%$ of ethanol. Comparatively with maceration, the microwave system was a faster solution, conducting to slightly higher catechin yields, but using higher temperatures to reach similar values. The ultrasound method was the least effective solution, yielding $0.71 \pm 0.1 \mathrm{mg} / \mathrm{g} \mathrm{dw}$ of catechin at $42.4 \pm 3.6 \mathrm{~min}, 314.9 \pm 21.2 \mathrm{~W}$ and $40.3 \pm 3.8 \%$ ethanol. The results highlight the potential of using $A$. unedo fruits bio-residues as a productive source of catechin.
\end{abstract}

(c) 2016 Elsevier B.V. All rights reserved.

\section{Introduction}

The small tree of Arbutus unedo L. (known as strawberry tree), belonging to the Ericaceae family, is a native species from the Mediterranean region. It produces an edible reddish sweet and tasty berry which is, when fully matured, rich in nutritional properties and has several medicinal effects, as astringent, diuretic and antiseptic properties (Ziyyat et al., 2002). Some authors have reported the presence of phenolic compounds in $A$. unedo fruits (Alarcão-E-Silva et al., 2001; Fortalezas et al., 2010; Guimarães et al., 2013; Pabuçcuoğlu et al., 2003; Pawlowska et al., 2006; Ruiz-Rodríguez et al., 2011), in particular catechins (monomeric flavan-3-ols and procyanidins polymeric flavan-3-ols) (Gadkari and

\footnotetext{
* Corresponding author.

E-mail address: iferreira@ipb.pt (I.C.F.R. Ferreira).
}

Balaraman, 2015; Guimarães et al., 2013; Pallauf et al., 2008). Catechins are flavan-3-ols that have attracted attention particularly due to their relative high antioxidant capacity (Aron and Kennedy, 2008). Several studies pointed out the interest of using catechins for health benefits, such as cancer prevention and plasma oxidation, as well as obesity control (Higdon and Frei, 2003; Hirasawa and Takada, 2004; Lotito and Fraga, 1998; Nagao et al., 2009). However, flavan-3-ols, and particularly catechin, are susceptible to degradation under various conditions, highlighting the importance of optimizing the extraction conditions to maximize the yield in these compounds (Ananingsih et al., 2013).

A broad spectrum of solid-liquid procedures is available for the extraction and isolation of new functional ingredients (Galanakis, 2012). However, some techniques comprise disadvantages requiring long times, large solvent consumption and leading to thermal degradation of phenolic compounds (Alonso-Salces et al., 2001; Dai and Mumper, 2010; Ince et al., 2013). The choice of the extraction 
solvent has also impact in extraction yield. Catechins are generally extracted with water, polar organic solvents, and aqueous organic solvent mixtures (Piñeiro et al., 2004; Vuong et al., 2010). Maceration extraction (ME) is a conventional method frequently used in the extraction of bioactive compounds. The procedure consists in stirring the sample in a solvent for a certain period of time and at a specific temperature. It is a simple technique, but very often requires long time periods and high temperatures. To overcome these drawbacks, alternative extraction methods are being proposed, such as microwave and ultrasound based techniques (Galanakis, 2013). Ultrasound-assisted extraction (UAE) is a technique that is increasingly used in chemical and food industries (Chemat et al., 2017). This technique has advantages such as being faster than conventional extraction methodologies, it is energetically less demanding and often permits the reduction in the solvent consumption. Adding to this, it generally results in extracts with improved purity and yield. Such advantages result from the process principle that is based on cavitation effects causing the rupture of plant cell walls, thus increasing the contact area between the solid and solvent (Ghasemzadeh et al., 2014; Herrera and Luque De Castro, 2004; Pingret et al., 2012). On the other hand, microwaveassisted extraction (MAE) is a process that facilitates the partition of the sample compounds into the solvent, decreasing the extraction time and temperature, and increasing the process efficiency using lower amounts of solvent (Li et al., 2013a). This method has been employed in the extraction of medicinal herbal compounds (Chen et al., 2008; Dai and Mumper, 2010; Proestos and Komaitis, 2008).

ME, MAE and UAE depend on several process variables whose values cannot be generalized for all matrices due to their specificity in terms of composition and target compounds (Jacotet-Navarro et al., 2016). Thus optimization of process variables is needed to select the best conditions to ensure a maximum yield, minimum time consumption, energy and solvent, obtaining the maximum benefit from the technique (Li et al., 2013b). Traditionally, optimization is achieved by monitoring the influence of one factor at a time. However, by using the response surface methodology (RSM), optimization is done simultaneously and in a multivariable form; the interaction effects between the factors can be assessed allowing a much more precise identification of the optimal conditions. The RSM, by means of mathematical equations, can describe the behaviour of the various variables and forecast the results for the system (Bezerra et al., 2008; Ferreira et al., 2007; Kalil and Maugeri, 2000).

The present study aims to optimize catechin extraction yield from $A$. unedo fruits to be considered for food, pharmaceutical and cosmetic industries. Different extraction methodologies such as ME, MAE and UAE were studied and compared. The joint effect of the relevant variables for each technique, to maximize catechin extraction yield, was described through RSM, contributing to the understanding of the real potential of catechin obtainment from $A$. unedo for industrial applications.

\section{Materials and methods}

\subsection{Source material}

The fruits of Arbutus unedo L. (strawberry tree) from Ericaceae were gathered in the Natural Park of Montesinho territory, in Trásos-Montes, North-eastern Portugal. The botanical identification was confirmed by Dr. Ana Maria Carvalho (School of Agriculture, Polytechnic Institute of Bragança, Trás-os-Montes, Portugal) according with a previous report of the authors (Guimarães et al., 2013). The fruits were lyophilized (FreeZone 4.5, Labconco, Kansas
City, MO, USA) and stored in a deep-freezer at $-20^{\circ} \mathrm{C}$ for subsequent analyses.

\subsection{Standards and reagents}

Formic acid and acetonitrile of HPLC grade from Fisher Scientific (Lisbon, Portugal) were used. Catechin standard was purchased from Sigma (St. Louis, MO, USA). Water was treated in a Milli-Q water purification system (TGI Pure Water Systems, Greenville, SC, USA). All other chemicals and solvents were of analytical grade and purchased from common suppliers.

\subsection{Extraction techniques}

From a combination of single variable preliminary experiments, previous extractions performed in our laboratory and bibliographic survey, the relevant variables and the appropriate tested ranges for each of the studied extraction techniques were selected and tested. A detailed description of the study ranges for the selected variables in each technique (RSM design) are described in Table A1 (Supplemental material section). The solid/solvent ratio was kept constant $(50 \mathrm{~g} / \mathrm{L})$ for all techniques. The used solvent was an ethanol/water mixture characterized in terms of ethanol content.

\subsubsection{Maceration extraction (ME)}

The lyophilized powdered fruit samples $(1 \mathrm{~g})$ were placed in a beaker with $20 \mathrm{~mL}$ of solvent in order to obtain the desired solid/liquid ratio $(50 \mathrm{~g} / \mathrm{L})$. The beaker was placed in a thermostated water bath under continuous electro-magnetic stirring for the required time period. The variables and ranges tested were: time ( $t$ or $\left.X_{1}, 20-150 \mathrm{~min}\right)$, temperature $\left(T\right.$ or $X_{2}, 20-90^{\circ} \mathrm{C}$ ) and ethanol percentage ( $S$ or $X_{3}, 0-100 \%$ ).

\subsubsection{Microwave-assisted extraction (MAE)}

MAE process was performed using a Biotage Initiator Microwave (Biotage $^{\circledR}$ Initiator ${ }^{+}$, Uppsala, Sweden) using closed vessels. The lyophilized powdered samples $(1 \mathrm{~g})$ were extracted with $20 \mathrm{~mL}$ of solvent (solid/solvent ratio $50 \mathrm{~g} / \mathrm{L}$ ). In microwave systems the pressure and $T$ are correlated and the applied power linked to the needed $t$ to reach the selected $T$ or pressure. In consequence, $T$ was selected as the main variable and the microwave power was set to $400 \mathrm{~W}$. Under the selected conditions, the needed $t$ to reach the selected $T$ was always less than $20 \mathrm{~s}$ thus guarantying a fast heating process (this time can be neglected face to the studied extraction time range). Therefore, the final variables and ranges tested were $t$ $\left(X_{1}, 1.6-45 \mathrm{~min}\right), T\left(X_{2}, 50-145^{\circ} \mathrm{C}\right)$ and $S\left(X_{3}, 0-100 \%\right)$.

\subsubsection{Ultrasound-assisted extraction (UAE)}

The UAE was carried out in an ultrasonic device (QSonica sonicators, model CL-334, Newtown, CT, USA). The lyophilized powdered samples $(2.5 \mathrm{~g}$ ) were extracted with $50 \mathrm{~mL}$ (solid/solvent ratio $50 \mathrm{~g} / \mathrm{L}$ ) by the ultrasonic device at different times ( $t$ or $X_{1}$, 5 to $55 \mathrm{~min}$ ) and at different ultrasound power ranges ( $P$ or $X_{2}$, $100-400 \mathrm{~W}$ ) according to an ethanol content ( $S$ or $\left.X_{3}, 0-100 \%\right)$ while temperature was monitored in order to be below $30-35^{\circ} \mathrm{C}$.

\subsection{Extract purification}

The collected extracts were filtered through a Whatman paper filter $n^{\circ} 4$. Then, the filtered material was dried at $40^{\circ} \mathrm{C}$ in a rotary evaporator Büchi R-210 (Flawil, Switzerland). For purification, a $C_{18}$ SepPak $^{\circledR}$ Vac 3 cc cartridge (Phenomenex) was used. After being activated with ethanol followed by water; sugars and more polar substances were removed by passing the column with $10-20 \mathrm{~mL}$ of water. Then the purified extract was further eluted with $10-15 \mathrm{~mL}$ 
of ethanol. The purified extract was dried at $40^{\circ} \mathrm{C}$ to remove ethanol.

\subsection{Catechin quantification by HPLC-PDA}

The samples obtained during the extraction optimization studies were analysed using a Shimadzu 20A series UFLC (Shimadzu Corporation, Kyoto, Japan) with a quaternary pump and a photodiode array detector (PDA) coupled to an LC solution software data-processing station. Separation was achieved using a Waters Spherisorb S3 ODS-2C 18 , $(3 \mu \mathrm{m}, 4.6 \mathrm{~mm} \times 150 \mathrm{~mm})$ column operating at $35^{\circ} \mathrm{C}$. The used mobile phase was a mixture of formic acid in water $0.1 \%(A)$ and $100 \%$ of acetonitrile (B), and the established elution gradient was as follows: $15 \%$ B for $5 \mathrm{~min}, 15 \%$ B to $20 \%$ B over $5 \mathrm{~min}, 20-25 \%$ B over $10 \mathrm{~min}, 25-35 \%$ B over $10 \mathrm{~min}, 35-50 \%$ B for $10 \mathrm{~min}$, and column re-equilibration ( $15 \mathrm{~min}$ ), using a flow rate of $0.5 \mathrm{~mL} / \mathrm{min}$. Detection was carried out in the PDA at $280 \mathrm{~nm}$ as preferred wavelength. Catechin was identified by comparing its UV spectra and retention times with the ones of a commercial standard as reported previously (Guimarães et al., 2013). The quantitative analysis was performed using a calibration curve based on catechin ( $\left.\mathrm{y}=66243 \mathrm{x}-343411 ; R^{2}=0.999\right)$. Results were expressed in $\mathrm{mg}$ of catechin per $\mathrm{g}$ of dry fruit weight $(\mathrm{mg} / \mathrm{g} \mathrm{dw})$.

\subsection{Response surface methodology}

\subsubsection{Experimental design}

For each extraction technique three variables were selected as the relevant ones. Those variables were studied in conjunction with a structured experimental design criteria (Box and Hunter, 1957) using a response surface methodology. Initially, three RSM variables were applied for each technique to optimize the extracting conditions. If the tested experimental range failed to provide a global optimum in any of the three variables, a relative optimum within the tested range was attempted through another RSM design involving the unresolved variable combined with the other relevant variables of the extraction system in a complementary two variables RSM design. Therefore, for complex scenarios, the two different experimental designs used for the optimization of the extraction conditions in each tested technique were as follows:

a) For the analysis of three variables $\left(X_{1-3}\right)$ : a circumscribed central composite design (CCCD) was used. In this design the experimental points are generated on a sphere around the centre point. This design requires 5 levels for each factor and 3 replicates per coordinate.

b) For the analysis of two variables $\left(X_{1-2}\right)$ : a full factorial design (FFD) with three replicates per condition was used. The structure of a FFD implies that all combinations of three values, for each factor, are studied (minimum, mean and maximum).

For both RSM design, the centre point is assumed as a value close to the optimum position for the response, being repeated in order to maximize the prediction precision (Box et al., 2005). Experimental runs were randomized to minimize the effects of unexpected variability in the observed responses. A detailed description of the mathematical expressions to calculate the design distribution and to decode and code the tested variable's ranges can be found in the Appendix section.

\subsubsection{Mathematical modelling}

Independently of the RSM used (two or three variables) the model for the analysis of the produced responses follows this second-order polynomial equation:

$$
Y=b_{0}+\sum_{i=1}^{n} b_{i} X_{i}+\sum_{\substack{i=1 \\ j>i}}^{n-1} \sum_{j=2}^{n} b_{i j} X_{i} X_{j}+\sum_{i=1}^{n} b_{i i} X_{i}^{2}
$$

where $Y$ is the dependent variable (response variable) to be modelled, $X_{i}$ and $X_{j}$ define the independent variables, $b_{0}$ is the constant coefficient, $b_{i}$ is the coefficient of linear effect, $b_{i j}$ is the coefficient of interaction effect, $b_{i i}$ the coefficients of quadratic effect and $n$ is the number of variables. Although the statistical consistent model parameters obtained are empirical and cannot be associated with a mechanistic meaning, they are useful to predict the results of untested operation conditions (Pinela et al., 2016). The sign of the effect marks the response performance. In this way, when a factor has a positive effect, the response is higher at the high level and when a factor has a negative effect, the response is lower at the high level. The higher the absolute value of a coefficient, the more important the weight of the corresponding variable (Heleno et al., 2016).

\subsubsection{Procedure to optimize the variables to a maximum response}

For optimization of catechin extraction, a maximized process of the model produced responses was achieved, using a simple method tool to solve non-linear problems (Heleno et al., 2016; Pinela et al., 2016). Limitations were made to the variable coded values to avoid unnatural conditions (i.e., times lower than 0 ).

\subsection{Numerical methods, statistical analysis and graphical illustrations}

All fitting procedures, coefficient estimations and statistical calculations were performed using a Microsoft Excel spreadsheet and the presented graphical illustrations were developed in the software DeltaGraph V6. Fitting and statistical analysis of the experimental results, according to the displayed equations, were carried out in four phases:

- Coefficients determination: Parametric estimates were obtained by minimization of the sum of quadratic differences between observed and model-predicted values, using the nonlinear leastsquare (quasi-Newton) method provided by the macro Solver in Microsoft Excel 2003 (Kemmer and Keller, 2010), which allows a quick testing of hypotheses and analysis of its consequences (Murado and Prieto, 2013).

- Coefficients significance: Determination of the parametric confidence intervals using the 'SolverAid' (Prikler, 2009). The model was simplified by excluding the values which were not statistically significant at $\alpha=0.05$.

- Model consistency: The Fisher $F$ test $(\alpha=0.05)$ was used to determine whether the constructed models were adequate to describe the observed data (Shi and Tsai, 2002).

- Other statistical assessment criteria: For confirmation of the uniformity of the model, the following criteria were applied: a) The 'SolverStat' macro (Comuzzi et al., 2003) which is used for the assessment of uncertainties related to parameter and model predictions; b) $R^{2}$ which is interpreted as the proportion of the variability of the dependent variable explained by the model; c) Adjusted coefficients of multiple determination $\left(R^{2}{ }_{\text {adj }}\right)$, which is a correction to $\mathrm{R}^{2}$ taking into account the number of variables used in the model; d) Bias and accuracy factors of all equations were calculated to evaluate the quality of fittings to experimen- 
tal data, such as the Mean Squared Error (MSE), the Root Mean Square of the Errors (RMSE) and the Mean Absolute Percentage Error(MAPE); e) the Durbin-Watson coefficient(DW) to test, if the residuals of the model are not auto-correlated; and f) the Analysis of Variance table (ANOVA) to evaluate the explanatory power of the variables.

\section{Results and discussion}

\subsection{Preliminary experiments to select the relevant variables and instrumental parameters to centre their experimental domain previous to the RSM application}

Although the existing previous reports dealing with the optimization of catechin extraction from natural matrices (Table 1 ), no reports could be found describing the conditions of catechin extraction from Arbutus unedo L. fruits. In addition, due to the compositional diversity of the material sources described in Table 1, the tested conditions cannot be directly extrapolated for catechin extraction from $A$. unedo fruits. Therefore, to find the conditions that maximize catechin extraction from Arbutus unedo L., it is necessary to take into account the variables that affect solid/solvent system techniques behaviour. These variables can be divided into non-intrinsic factors (solvent type, $S$ and solid to liquid ratio) and intrinsic factors ( $t$ and $T$ for the ME and MAE systems, and $t$ and $P$ for UAE system). Preliminary tests were examined individually to determine their experimental domain (keeping other ones constant) in order to obtain a proper RSM design by analyzing their general pattern responses.

In consequence, in all extracting systems, the non-intrinsic variables and ranges were selected as follows:

1) The extracting solvent type is a key factor for the separation of the desired compounds. Due to the catechin chemical structure, different solvent mixtures with water were used to maximize extraction yields; mainly, water with methanol, ethanol or acetone different contents (more details in Table 1). Due to green chemistry principles, binary mixtures of ethanol with water were selected as the extraction solvent. In all systems, the ethanol content in the water/ethanol mixture $(S)$ was tested from 0 to $100 \%$ and confirmed as impacting significantly the catechin extraction yield and, therefore, selected in the appropriate range.

2) With regard to solid/liquid ratio, the tested range was $1-60 \mathrm{~g} / \mathrm{L}$ lower values lead to an enhanced extraction yield, but also contribute to a significant waste of solvent. A higher solid/liquid ratio will result in lower catechin extraction yields but in a better rationalization of raw materials consumption. However, lower differences were found, discarding the solid/liquid ratio and selecting the $50 \mathrm{~g} / \mathrm{L}$ as the value to be used in all tested extraction techniques.

Concerning the intrinsic variables from the ME, MAE and UAE, a literature survey concerning the main ranges, as studied in similar processes (Table 1), was carried out. Although good conclusions can be derived from this report, results may be highly dependent on variations not foreseen in these studies where certain variables that remained constant, together with the variability in the used raw materials to extract catechin, can highly influence the process.

In conclusion, the first approach to optimize the efficiency of the ME, MAE and UAE processes for catechin extraction, was performed by the application of a RSM of three variables in a CCCD. Five levels of variation for the independent variables of $t$ (20-120 min), $T$ $\left(20-90{ }^{\circ} \mathrm{C}\right)$, and $S(0-100 \%)$ for ME and of $t(1-20 \mathrm{~min}), T\left(50-120^{\circ} \mathrm{C}\right)$, and $S(0-100 \%)$ for MAE and $t(5-55 \mathrm{~min}), P(100-400 \mathrm{~W})$, and $S$
(0-100\%) for UAE were used. A detailed description of the coded and natural values of the selected variables for each technique in the $C C C D$ with tree variables is presented in Table A1 (Supplemental material section).

\subsection{RSM output for a CCCD with three variables}

The results obtained according to the statistical $C C C D$ are shown in the first part of Table 2 for each of the computed extraction techniques. After fitting Eq. (1) to the response results of Table 2 using a non-linear least-squares procedure, the estimated parametric values, parametric intervals and numerical statistical criteria were obtained and presented in the first part of Table 3. Those coefficients, which showed effects with coefficient interval values $(\alpha=0.05)$ higher than the parameter value, were consider as nonsignificant (ns) and were not pondered for the model development.

Therefore, mathematical models were built, obtaining the following second-order polynomial equations according to Eq. (1) for each of the assessed extraction techniques:

$$
\begin{aligned}
& \text { for ME: } Y_{M E}=1.1+0.05 t+0.24 T-0.23 S / L-0.11 t^{2}-0.15 T^{2} \\
& \quad-0.13 S / L^{2}-0.1 t T \\
& \text { for MAE: } Y_{M A E}=0.66+0.09 t+0.08 T \\
& \quad-0.04 S / L-0.01 t^{2}-0.03 T^{2}-0.11 S / L^{2} \\
& +0.03 t T-0.04 t S / L-0.03 T S / L \\
& \text { for UAE: } Y_{U A E}=0.69+0.02 t+0.02 T-0.8 S / \\
& \quad L-0.02 t^{2}-0.03 T^{2}-0.13 S / L^{2}
\end{aligned}
$$

The Eqs. (2)-(4) translate the response patterns for each extraction technique showing highly complex sceneries (Table 3). Linear and quadratic effects are found playing an important and significant role in all extracting systems. Regarding the interactive effects, for ME system only the interaction between $t \& T$ was significant in a positive mode; for MAE all the variable interactions caused a significant effect (positive for $t \& T$, and negative for $t \& S$ and $T \&$ $S$ ); and for UAE no significant effects were found.

Fig. 1 shows the extraction results in $\mathrm{mg} / \mathrm{g} \mathrm{dw}$ of catechin, which is divided in three columns for each one of the tested techniques. Each column is divided into two subsections (A and B). The subsection A shows the combination of the three-dimensional response surface plots predicted with their respective second order polynomial equation described by Eqs. (2)-(4) as a function of each one of the involved variables. The binary action between variables is presented when the excluded variable is positioned at the centre of the experimental domain (see Table A1). Subsection B illustrates the capability to predict the obtained results and the residual distribution as a function of each one of the considered variables.

In almost all combinatory 3D responses of Fig. 1, the amount of extracted material increases to an optimum value and then decreases as a function of each one of the assessed independent variables. Therefore, in almost all combinations the optimum can be found at one single point along with the response, allowing computing the conditions that lead to the absolute maximum.

By applying a simple procedure considering restrictions to the experimental ranges, optimal conditions are found, as well as the maximal response values (first part of Table 4). For the ME system, the relative optimal $\left({ }^{*}\right)$ or absolute conditions found were at $88.3 \pm 31.8 \mathrm{~min}, 79.2 \pm 15.7^{\circ} \mathrm{C}$ and $23.1 \pm 3.7 \%$ ethanol, producing a maximum response value of $1.36 \pm 0.5 \mathrm{mg}$ of catechin/g dw. For MAE response, the optimal condition values were at ${ }^{*} 18.4 \pm 1.7 \mathrm{~min},{ }^{*} 118.6 \pm 21.3^{\circ} \mathrm{C}$ and $12.1 \pm 1.1 \%$ ethanol, 
Bibliographic summary of catechin content from different source materials using different extraction techniques and conditions.

\begin{tabular}{|c|c|c|c|c|c|c|c|c|c|}
\hline \multirow[t]{2}{*}{ TECHNIQUE APPLIED } & \multirow[t]{2}{*}{ SOURCE MATERIAL } & \multirow[t]{2}{*}{ PLANT PART } & \multicolumn{5}{|c|}{ EXTRACTION CONDITIONS } & \multirow{2}{*}{$\begin{array}{l}\text { CATECHIN CONTENT } \\
(\mathrm{mg} / \mathrm{g} \mathrm{dw}) \\
\end{array}$} & \multirow[t]{2}{*}{ REFERENCE } \\
\hline & & & Solvent & $\begin{array}{l}\text { Temperature } \\
\left({ }^{\circ} \mathrm{C}\right)\end{array}$ & $\begin{array}{l}\text { Power or } \\
\text { Frequency ( } k H z \text { or } \\
W)\end{array}$ & $p H$ & $\begin{array}{l}\text { Time } \\
\text { (min) }\end{array}$ & & \\
\hline \multirow{11}{*}{$\begin{array}{l}\text { ULTRASOUND ASSISTED } \\
\text { EXTRACTION }\end{array}$} & Apple & Pulp & Water & 40 & $25 \mathrm{kHz}$ & - & 45 to 90 & 0.030 to 0.075 & Mieszczakowska-Frąc et al. (2015) \\
\hline & Apple & Pomace & Water & 40 & $150 \mathrm{~W}$ & 3.8 & 40 & 0.15 & Pingret et al. (2012) \\
\hline & Curry & Leaves & $\begin{array}{l}\text { Methanol:Water } \\
(80: 20)\end{array}$ & 56 & $145 \mathrm{~W}$ & - & 20 & 0.48 & Ghasemzadeh et al. (2014) \\
\hline & Grape & Seeds & $\begin{array}{l}\text { Methanol:Water } \\
(75: 25)\end{array}$ & - & - & - & 15 & 0.41 & García-Marino et al. (2006) \\
\hline & Grape & Seeds & Methanol & 60 & - & - & 10 & 0.23 & Piñeiro et al. (2004) \\
\hline & Grape & Seeds & $\begin{array}{l}\text { Methanol:Water } \\
(10: 90)\end{array}$ & 30 & - & - & $30 \times 2$ & 0.65 & Palma and Taylor (1999) \\
\hline & Maritime pine & Plant & Water & 40 & - & 3.8 & 43 & 3.5 & Meullemiestre et al. (2016) \\
\hline & Melissa & Leaves & Water & - & $150 \mathrm{~W}$ & - & 20 & 2.01 & Ince et al. (2013) \\
\hline & Mushroon & & $\begin{array}{l}\text { Ethanol:Water } \\
(60: 40)\end{array}$ & 25 & - & - & 30 & 0.1 & Zhang et al. (2012) \\
\hline & Pistachio & Nut & Water & - & $35 \mathrm{kHz}$ & - & 30 & 0.05 & Garavand et al. (2015) \\
\hline & Strawberrie & Fruit & Acetone & - & $100 \mathrm{~W}$ & $<3$ & $0.5 \times 3$ & 0.015 & $\begin{array}{l}\text { Herrera and Luque De Castro } \\
(2004)\end{array}$ \\
\hline \multirow{8}{*}{$\begin{array}{l}\text { MACERATION ASSISTED } \\
\text { EXTRACTION }\end{array}$} & Apple & Pulp & Water & 40 & - & - & $45-90$ & 0.040 to 0.050 & Mieszczakowska-Frąc et al. (2015) \\
\hline & Apple & Pomace & Water & 40 & - & 3.8 & 40 & 0.115 & Pingret et al. (2012) \\
\hline & Folium eriobotryae & Fruit & Methanol & - & $700 \mathrm{~W}$ & - & 3 & 12.1 & Chen et al. (2008) \\
\hline & Grape & Seeds & $\begin{array}{l}\text { Methanol:Water } \\
(4: 1)\end{array}$ & 30 & - & - & 960 & 0.7 & Palma and Taylor (1999) \\
\hline & Green tea & Leaves & Water & 25 to 80 & - & $<6$ & 30 to 120 & 0.600 to 7.100 & Vuong et al. (2011) \\
\hline & Melissa & Leaves & Water & 40 & - & - & 1440 & 3.45 & Ince et al. (2013) \\
\hline & Mushroon & & $\begin{array}{l}\text { Ethanol:Water } \\
(60: 40)\end{array}$ & 25 & - & - & 720 & 0.1019 & Zhang et al. (2012) \\
\hline & Grape & Seeds & Methanol & 60 & - & - & 10 & 0.27 & Piñeiro et al. (2004) \\
\hline \multirow[t]{3}{*}{ HEAT REFLUX EXTRACTION } & F. eriobotryae & Fruit & Methanol & 80 & - & - & 3 & 7.34 & Chen et al. (2008) \\
\hline & Rosemary & Plant & $\begin{array}{l}\text { Methanol:Water } \\
(60: 40)\end{array}$ & 90 & - & - & 120 & 0.019 & Proestos and Komaitis (2008) \\
\hline & Mushroon & & $\begin{array}{l}\text { Ethanol:Water } \\
(60: 40)\end{array}$ & 90 & - & - & 50 & 0.1023 & Zhang et al. (2012) \\
\hline \multirow[t]{4}{*}{$\begin{array}{l}\text { MICROWAVE ASSISTED } \\
\text { EXTRACTION }\end{array}$} & Rosemary & Plant & $\begin{array}{l}\text { Methanol:Water } \\
(60: 40)\end{array}$ & - & $750 \mathrm{~W}$ & - & 4 & 0.025 & Proestos and Komaitis (2008) \\
\hline & Pistachio & Nut & Water & - & $800 \mathrm{~W}$ & - & 0.5 & 0.0467 & Garavand et al. (2015) \\
\hline & Melissa & Leaves & Water & - & $407 \mathrm{~W}$ & - & 5 & 1.353 & (Ince et al. (2013) \\
\hline & Mushroon & & $\begin{array}{l}\text { Ethanol:Water } \\
(60: 40)\end{array}$ & 110 & $500 \mathrm{~W}$ & - & 10 & 0.1079 & Zhang et al. (2012) \\
\hline \multirow{3}{*}{$\begin{array}{l}\text { PRESSURIZED LIQUID } \\
\text { EXTRACTION }\end{array}$} & Apple & Peel & Methanol & 40 & - & - & 5 & 0.043 & Alonso-Salces et al. (2001) \\
\hline & Apple & Pulp & Methanol & 40 & - & - & 5 & 0.018 & Alonso-Salces et al. (2001) \\
\hline & Grape & Seeds & Methanol & 130 & - & - & 10 & 1.82 & Piñeiro et al. (2004) \\
\hline $\begin{array}{r}\text { SUPRECRITICAL } \\
\text { EXTRACTION }\end{array}$ & Grape & Seeds & $\begin{array}{l}\text { Methanol:Water } \\
(10: 90)\end{array}$ & 55 & - & - & 60 & 0.865 & Palma and Taylor (1999) \\
\hline SUBCRITICAL EXTRACTION & Grape & Seeds & Water & $50,100,150$ & - & - & 30 & 0.14 to 0.47 & García-Marino et al. (2006) \\
\hline
\end{tabular}


MACERATION

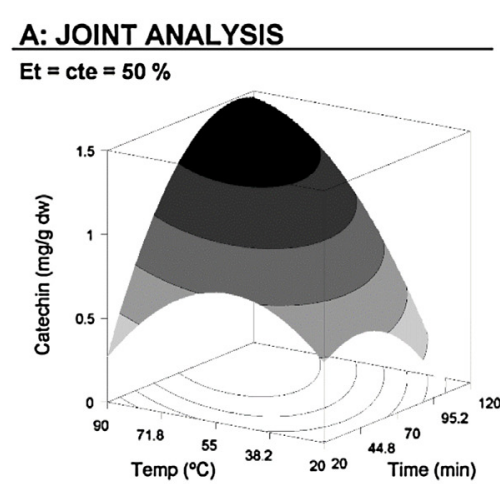

Temp $=$ cte $=85^{\circ} \mathrm{C}$

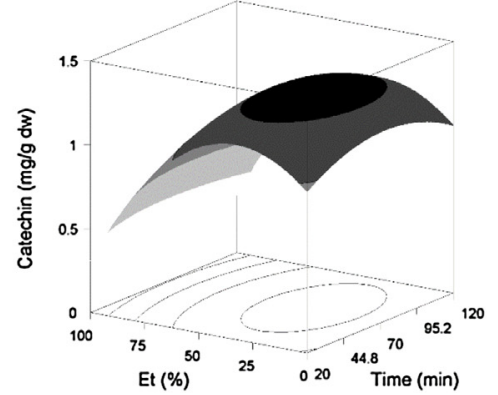

Time $=$ cte $=10 \mathrm{~min}$

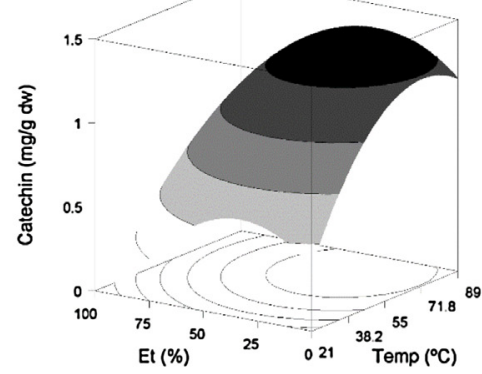

B: STATISTICAL DISTRIBUTION
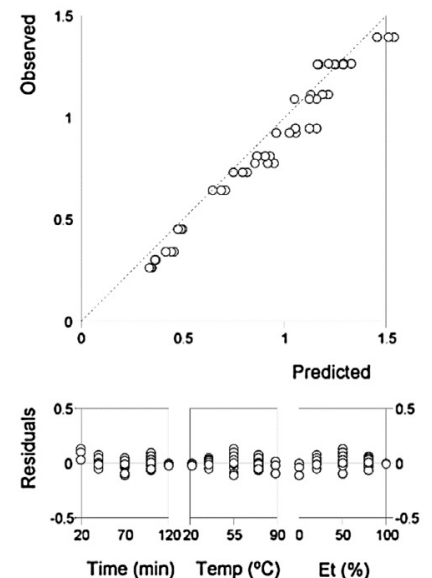

MICROWAVE

A: JOINT ANALYSIS

$\mathrm{Et}=\mathrm{cte}=\mathbf{5 0} \%$

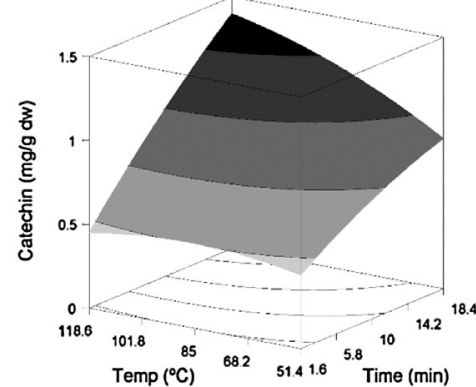

Temp $=$ cte $=85^{\circ} \mathrm{C}$

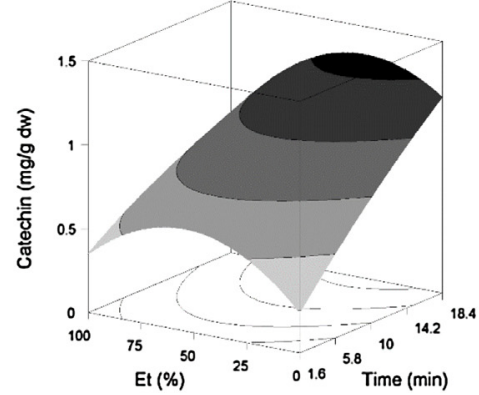

Time $=$ cte $=10 \mathrm{~min}$

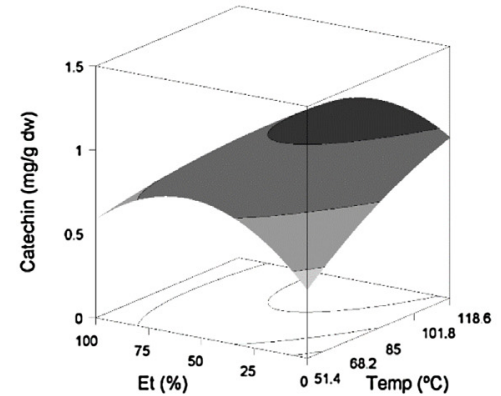

B: STATISTICAL DISTRIBUTION
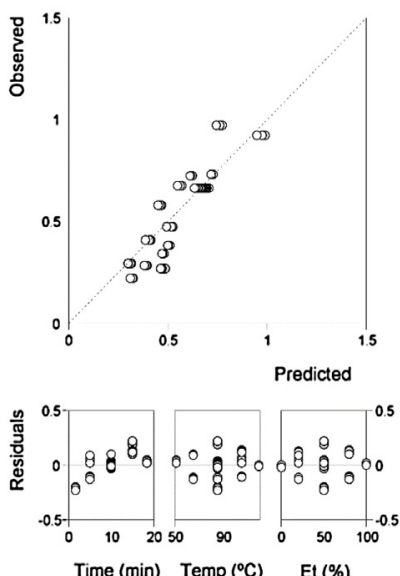

ULTRASOUND

A: JOINT ANALYSIS

Et $=$ cte $=\mathbf{5 0} \%$

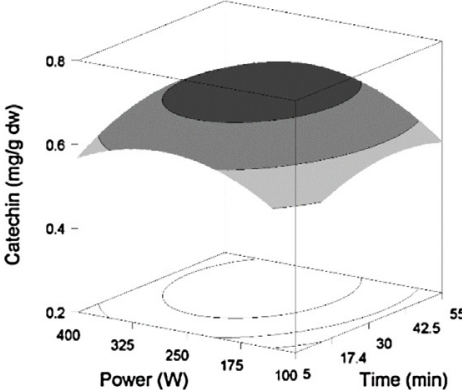

Power $=\mathrm{cte}=\mathbf{2 5 0 \mathrm { W }}$

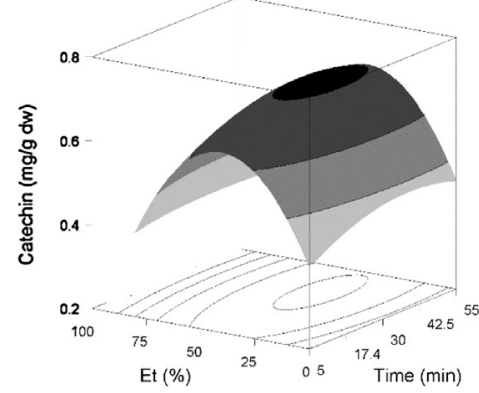

Time $=$ cte $=\mathbf{3 0} \mathrm{min}$

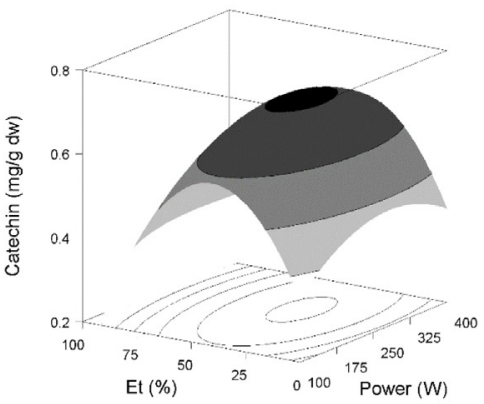

B: STATISTICAL DISTRIBUTION
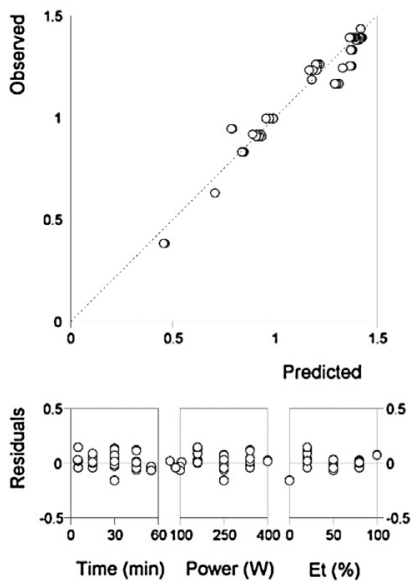

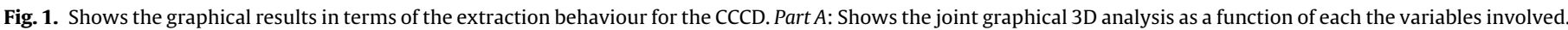

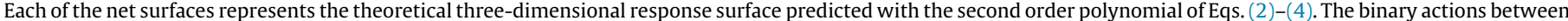

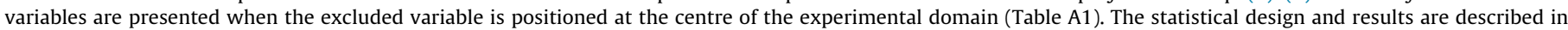

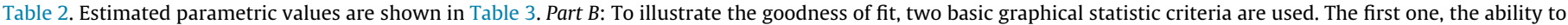

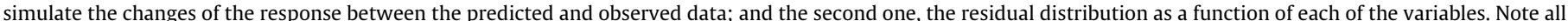
the differences in the axes scales. 
Table 2

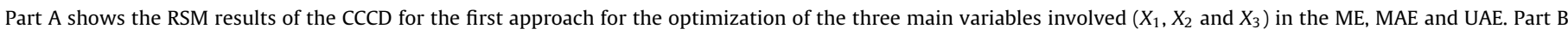

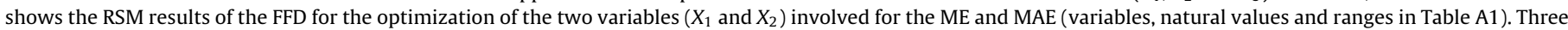
replicates $\left(r_{1-3}\right)$ were performed for each condition for each technique.

\begin{tabular}{|c|c|c|c|c|c|c|c|c|c|c|c|}
\hline \multicolumn{3}{|c|}{ VARIABLE CODED VALUES } & \multicolumn{9}{|c|}{ CATECHIN CONTENT (mg/g dw) } \\
\hline \multirow[b]{2}{*}{$X_{1}$} & \multirow[b]{2}{*}{$X_{2}$} & \multirow[b]{2}{*}{$X_{3}$} & \multicolumn{3}{|c|}{ MACERATION } & \multicolumn{3}{|c|}{ MICROWAVE } & \multicolumn{3}{|c|}{ ULTRASOUND } \\
\hline & & & $r_{1}$ & $r_{2}$ & $r_{3}$ & $r_{1}$ & $r_{2}$ & $r_{3}$ & $r_{1}$ & $r_{2}$ & $r_{3}$ \\
\hline \multicolumn{12}{|c|}{ A) CIRCUMSCRIBED CENTRAL COMPOSITE DESIGN (CCCD) } \\
\hline-1 & -1 & -1 & 0.84 & 0.86 & 0.87 & 0.31 & 0.32 & 0.33 & 0.66 & 0.65 & 0.65 \\
\hline 1 & -1 & -1 & 0.74 & 0.76 & 0.77 & 0.55 & 0.56 & 0.57 & 0.67 & 0.67 & 0.67 \\
\hline-1 & 1 & -1 & 1.12 & 1.15 & 1.16 & 0.50 & 0.50 & 0.51 & 0.68 & 0.69 & 0.69 \\
\hline 1 & 1 & -1 & 1.32 & 1.35 & 1.36 & 0.95 & 0.98 & 0.99 & 0.69 & 0.69 & 0.69 \\
\hline-1 & -1 & 1 & 0.38 & 0.39 & 0.40 & 0.38 & 0.39 & 0.40 & 0.42 & 0.42 & 0.42 \\
\hline 1 & -1 & 1 & 0.30 & 0.30 & 0.30 & 0.45 & 0.46 & 0.47 & 0.45 & 0.47 & 0.46 \\
\hline-1 & 1 & 1 & 0.65 & 0.67 & 0.68 & 0.47 & 0.47 & 0.48 & 0.47 & 0.45 & 0.46 \\
\hline 1 & 1 & 1 & 0.94 & 0.97 & 0.99 & 0.61 & 0.61 & 0.62 & 0.48 & 0.50 & 0.49 \\
\hline-1.68 & 0 & 0 & 0.81 & 0.84 & 0.85 & 0.49 & 0.46 & 0.47 & 0.61 & 0.60 & 0.60 \\
\hline 1.68 & 0 & 0 & 0.99 & 1.03 & 1.04 & 0.74 & 0.76 & 0.77 & 0.71 & 0.71 & 0.71 \\
\hline 0 & -1.68 & 0 & 0.40 & 0.41 & 0.41 & 0.49 & 0.52 & 0.53 & 0.58 & 0.60 & 0.59 \\
\hline 0 & 1.68 & 0 & 1.18 & 1.21 & 1.23 & 0.72 & 0.72 & 0.73 & 0.70 & 0.70 & 0.70 \\
\hline 0 & 0 & -1.68 & 1.14 & 1.17 & 1.19 & 0.39 & 0.41 & 0.41 & 0.39 & 0.40 & 0.39 \\
\hline 0 & 0 & 1.68 & 0.39 & 0.39 & 0.4 & 0.30 & 0.31 & 0.32 & 0.23 & 0.23 & 0.23 \\
\hline 0 & 0 & 0 & 1.17 & 1.21 & 1.23 & 0.63 & 0.64 & 0.65 & 0.69 & 0.69 & 0.69 \\
\hline 0 & 0 & 0 & 1.17 & 1.21 & 1.23 & 0.65 & 0.67 & 0.68 & 0.68 & 0.68 & 0.68 \\
\hline 0 & 0 & 0 & 1.17 & 1.21 & 1.23 & 0.66 & 0.70 & 0.71 & 0.71 & 0.71 & 0.71 \\
\hline 0 & 0 & 0 & 1.17 & 1.21 & 1.23 & 0.66 & 0.68 & 0.69 & 0.69 & 0.70 & 0.70 \\
\hline 0 & 0 & 0 & 1.17 & 1.21 & 1.23 & 0.67 & 0.68 & 0.69 & 0.71 & 0.71 & 0.71 \\
\hline 0 & 0 & 0 & 1.17 & 1.21 & 1.23 & 0.67 & 0.68 & 0.69 & 0.69 & 0.70 & 0.70 \\
\hline \multicolumn{12}{|c|}{ B) FULL FACTORIAL DESIGN (FFD) } \\
\hline-1 & -1 & - & 1.16 & 1.16 & 1.16 & 0.93 & 0.94 & 0.94 & - & - & - \\
\hline 0 & -1 & - & 1.24 & 1.25 & 1.25 & 1.35 & 1.36 & 1.37 & - & - & - \\
\hline 1 & -1 & - & 0.83 & 0.83 & 0.83 & 1.51 & 1.52 & 1.53 & - & - & - \\
\hline-1 & 0 & - & 1.30 & 1.30 & 1.30 & 1.22 & 1.23 & 1.24 & - & - & - \\
\hline 0 & 0 & - & 1.40 & 1.40 & 1.40 & 1.60 & 1.61 & 1.62 & - & - & - \\
\hline 1 & 0 & - & 1.00 & 1.01 & 1.00 & 1.72 & 1.74 & 1.75 & - & - & - \\
\hline-1 & 1 & - & 1.27 & 1.27 & 1.27 & 1.19 & 1.20 & 1.20 & - & - & - \\
\hline-1 & -1 & - & 1.38 & 1.38 & 1.38 & 1.53 & 1.54 & 1.54 & - & - & - \\
\hline
\end{tabular}

Table 3

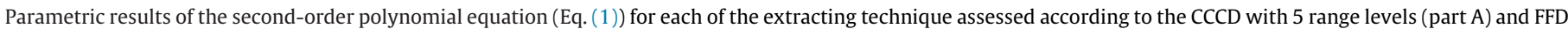

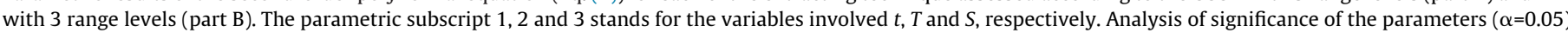
are presented in natural values. Additionally, the statistical information of the fitting procedure to the model is presented.

\begin{tabular}{|c|c|c|c|c|c|c|}
\hline \multirow[t]{3}{*}{ COEFFICIENTS } & & \multicolumn{5}{|l|}{ RESPONSES } \\
\hline & & \multicolumn{3}{|c|}{ CENTRAL COMPOSITE DESIGN } & \multicolumn{2}{|c|}{ FULL FACTORIAL DESIGN } \\
\hline & & MACERATION & MICROWAVE & ULTRASOUND & MACERATION & MICROWAVE \\
\hline \multicolumn{7}{|c|}{ Fitting coefficients obtained } \\
\hline Intercept & $b_{0}$ & $1.126 \pm 0.10$ & $0.668 \pm 0.37$ & 0.6960 .016 & $1.351 \pm 0.02$ & $1.613 \pm 0.02$ \\
\hline \multirow[t]{3}{*}{ Linear effect } & $b_{1}$ & $0.051 \pm 0.01$ & $0.091 \pm 0.02$ & 0.0190 .01 & $0.076 \pm 0.01$ & $0.089 \pm 0.01$ \\
\hline & $b_{2}$ & $0.241 \pm 0.06$ & $0.076 \pm 0.02$ & 0.0220 .01 & $-0.114 \pm 0.01$ & $0.219 \pm 0.01$ \\
\hline & $b_{3}$ & $-0.235 \pm 0.06$ & $-0.034 \pm 0.02$ & -0.0840 .01 & & \\
\hline \multirow[t]{3}{*}{ Quadratic effect } & $b_{11}$ & $-0.112 \pm 0.03$ & $-0.009 \pm 0.00$ & -0.0170 .01 & $-0.079 \pm 0.01$ & $-0.184 \pm 0.02$ \\
\hline & $b_{22}$ & $-0.154 \pm 0.06$ & $-0.025 \pm 0.00$ & -0.030 .01 & $-0.227 \pm 0.01$ & $-0.15 \pm 0.02$ \\
\hline & $b_{33}$ & $-0.13 \pm 0.06$ & $-0.111 \pm 0.02$ & -0.1290 .01 & & \\
\hline \multirow[t]{3}{*}{ Interactive effect } & $b_{12}$ & $0.09 \pm 0.08$ & $0.025 \pm 0.02$ & ns & $0.017 \pm 0.01$ & $-0.041 \pm 0.01$ \\
\hline & $b_{13}$ & ns & $-0.042 \pm 0.02$ & $n s$ & & \\
\hline & $b_{23}$ & $n s$ & $-0.025 \pm 0.02$ & $n s$ & & \\
\hline \multicolumn{7}{|c|}{ Statistical information of the fitting analysis } \\
\hline \multicolumn{2}{|c|}{ Obs } & 60 & 60 & 60 & 27 & 27 \\
\hline \multicolumn{2}{|l|}{$d f$} & 51 & 49 & 52 & 20 & 20 \\
\hline \multicolumn{2}{|l|}{$R^{2}$} & 0.967 & 0.9655 & 0.9479 & 0.986 & 0.9879 \\
\hline \multicolumn{2}{|l|}{$R^{2} a d j$} & 0.9326 & 0.9593 & 0.9386 & 0.9625 & 0.9631 \\
\hline \multicolumn{2}{|l|}{$M E C$} & 0.131 & 0.0311 & 0.022 & 0.0864 & 0.049 \\
\hline \multicolumn{2}{|l|}{ RMSE } & 0.362 & 0.1762 & 0.1483 & 0.294 & 0.2213 \\
\hline \multicolumn{2}{|l|}{ MAPE } & 2.0099 & 4.0771 & 4.6536 & 0.3814 & 0.0917 \\
\hline \multicolumn{2}{|l|}{$D W$} & 1.0598 & 2.5446 & 1.6565 & 0.236 & 2.9929 \\
\hline
\end{tabular}

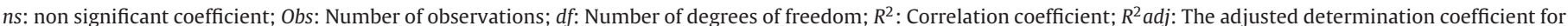

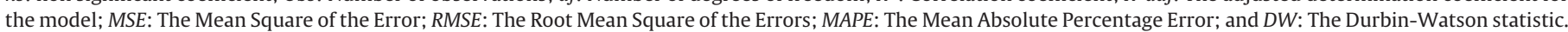

producing a maximum response of $0.97 \pm 0.2 \mathrm{mg}$ catechin $/ \mathrm{g}$ dw. For UAE, the optimal conditions were found at $42.4 \pm 4.1 \mathrm{~min}$,
$314.9 \pm 21.2 \mathrm{~W}$ and $40.3 \pm 3.8 \%$ ethanol obtaining a maximum response of $0.71 \pm 0.1 \mathrm{mg}$ catechin $/ \mathrm{g} \mathrm{dw}$. 
Table 4

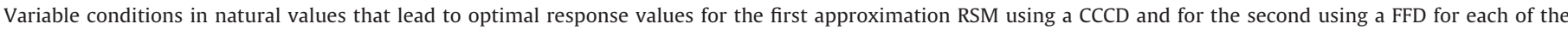
extracting techniques assessed.

\begin{tabular}{|c|c|c|c|c|c|}
\hline \multirow[t]{2}{*}{ CRITERIA } & \multicolumn{3}{|c|}{ OPTIMAL VARIABLE CONDITIONS } & \multicolumn{2}{|c|}{ OPTIMUM RESPONSE } \\
\hline & $X_{1}: t(\min )$ & $X_{2}: T\left({ }^{\circ} C\right)$ or $P(W)$ & $X_{3}: S(\%)$ & & \\
\hline \multicolumn{6}{|c|}{ Individual optimal variable conditions for the CCCD: } \\
\hline Maceration & $88.3 \pm 31.8$ & $79.2 \pm 15.7^{*}$ & $23.1 \pm 3.7$ & $1.36 \pm 0.5$ & $m g / g d w$ \\
\hline Microwave & $18.4 \pm 1.7^{*}$ & $118.6 \pm 21.3^{*}$ & $12.1 \pm 1.1$ & $0.97 \pm 0.2$ & $m g / g d w$ \\
\hline Ultrasound & $42.4 \pm 4.1$ & $314.9 \pm 21.2$ & $40.3 \pm 3.8$ & $0.71 \pm 0.1$ & $m g / g d w$ \\
\hline \multicolumn{6}{|c|}{ Individual optimal variable conditions for the FFD: } \\
\hline Maceration & $93.2 \pm 3.7$ & $79.6 \pm 5.2$ & - & $1.38 \pm 0.1$ & $m g / g d w$ \\
\hline Microwave & $42.2 \pm 4.1$ & $137.1 \pm 8.1$ & - & $1.70 \pm 0.3$ & $m g / g d w$ \\
\hline \multicolumn{6}{|c|}{ Global optimal variable conditions for the combination of the CCCD and FFD responses: } \\
\hline Maceration & $93.2 \pm 3.7$ & $79.6 \pm 5.2$ & $23.1 \pm 3.7$ & $1.38 \pm 0.1$ & $m g / g d w$ \\
\hline Microwave & $42.2 \pm 4.1$ & $137.1 \pm 8.1$ & $12.1 \pm 1.1$ & $1.70 \pm 0.3$ & $m g / g d w$ \\
\hline Ultrasound & $42.4 \pm 3.6$ & $314.9 \pm 21.2$ & $40.3 \pm 3.8$ & $0.71 \pm 0.1$ & $m g / g d w$ \\
\hline
\end{tabular}

Although the CCCD was based on preliminary tests and bibliographic results, in the produced responses, it was not possible to find the optimal conditions for all variables in the tested extraction techniques. The main reason is due to the fact that the experiments were conducted at one factor of the time analysis and the obtained patterns do not take into account the interactive effects. Only experimental designs based on multivariable analysis (such as the RSM) can produce patterns that integrate the interactions between the variables. The positive interactions between the $t \& T$ in $\mathrm{ME}$ and MAE systems produced an additional effect since the responses were not either conclusive enough (ME case) or absolutely optimized (MAE case) within the tested variable's range, finding large confidence intervals for some optimal values (ME case) or relative optimum conditions (MAE case) for the variables $t$ and $T$. The lack of a clear absolute optimum in the provided solution, forces the acceptance of one of the following solutions: 1) an unreliable optimum and/or a relative optimum; 2) to use the predicting absolute optimum values of the developed mathematical model; or 3) to re-design a second RSM around the ranges that seem to be the optimal ones in order to find the experimental values that would help to find the absolute optimum of these variables in which the first optimization approach failed. In this study, solution (3) was chosen and further experiments were performed using a RSM based in a FFD for the specific analysis of the interaction of $t$ and $T$ variables in ME and MAE systems.

\subsection{Final optimization of ME and MAE using a RSM based in FFD with the $t$ and $T$ variables}

The variables range of $t$ and $T$ for the FFD were expanded according to the $C C C D$ results (experimental domain in second part of Table A1, supplemental material). The obtained results, according to the statistical FFD for ME and MAE, are shown in the second part of Table 2 for each of the computed extraction technique. Identically to the previous RSM approach, Eq. (1) was used to fit the results of Table 2 using a non-linear least-squares procedure. The estimated parametric values, parametric intervals and numerical statistical criteria were obtained and presented in the second part of Table 3. Mathematical models were built, obtaining the following secondorder polynomial equations according to Eq. (1) for each one of the assessed extraction technique:

for ME: $Y_{M E}=1.35+0.08 t-0.11 T-0.08 t^{2}-0.23 T^{2}+0.08 t T(5)$
for MAE: $Y_{M A E}=1.6+0.09 t+0.2 T-0.18 t^{2}-0.15 T^{2}-0.04 t T(6)$

Eqs. (5) and (6) complete the response patterns for each extraction technique showing nearly identical sceneries to those previously found for the $C C C D$ approach, but covering a more extensive range of the variables, allowing to find the extraction conditions that lead to a reliable absolute optimum for catechin extraction. Linear and quadratic effects were found to play an important and significant role in all extraction systems. Regarding the interactive effects of $t$ and $T$, for ME and MAE, significant effects were corroborated in a positive and negative form, respectively.

Fig. 2 shows the catechin extraction results for each one of the tested techniques (ME and MAE). For each technique Fig. 2 is divided into three sections:

- Section A shows the catechin extraction yield ( $\mathrm{mg} / \mathrm{g} \mathrm{dw}$ ) as a function of $t$ and $T$ variables. Points $(\bullet)$ represent the obtained experimental results according to the described statistical design. The net surface represents the theoretical three-dimensional response surface predicted with the second order polynomial Eqs. (5) and (6). Estimated parametric values are shown in the second part of Table 3 . The binary action between variables is presented when the excluded variable is positioned at the centre of the experimental domain.

- Section B presents two-dimensional representation of the fitting results of Eqs. (5) and (6) (solid line) to the experimental points ( $\square$ minimum, $\diamond$ medium and $\triangle$ maximum variable values) of the combined effect of $t$ and $T$ on the catechin extraction yield ( $\mathrm{mg} / \mathrm{g}$ dw).

- Section C shows an illustration for the statistical robustness of the reached solution. Two basic graphical criteria are used: the ability to simulate the response changes and the residual distribution as a function of each of one of the variables.

In both techniques (ME and MAE) the $T$ and $t$ variables significantly affected catechin extraction. Catechin extraction efficiency increased with the increase of $T$ and $t$ until an absolute optimum from which it decreased. By applying a simple procedure with restrictions to the tested experimental ranges, the optimal condition results can be found, as well as, the maximal catechin yield response values for each technique, being presented in the second part of Table 4. For the ME system, the optimal absolute conditions found were at $93.2 \pm 3.7 \mathrm{~min}$ and $79.6 \pm 5.2^{\circ} \mathrm{C}$ (at a constant $24 \%$ of ethanol) producing a maximum response value of $1.38 \pm 0.1 \mathrm{mg}$ of catechin $/ \mathrm{g} \mathrm{dw}$. For the MAE response, the optimal condition values were at $42.2 \pm 4.1 \mathrm{~min}$ and $137.1 \pm 8.1^{\circ} \mathrm{C}$ (at a constant $12 \%$ of ethanol) producing a maximum response of $1.70 \pm 0.3 \mathrm{mg}$ of catechin/g dw. 


\section{A: JOINT ACTION}
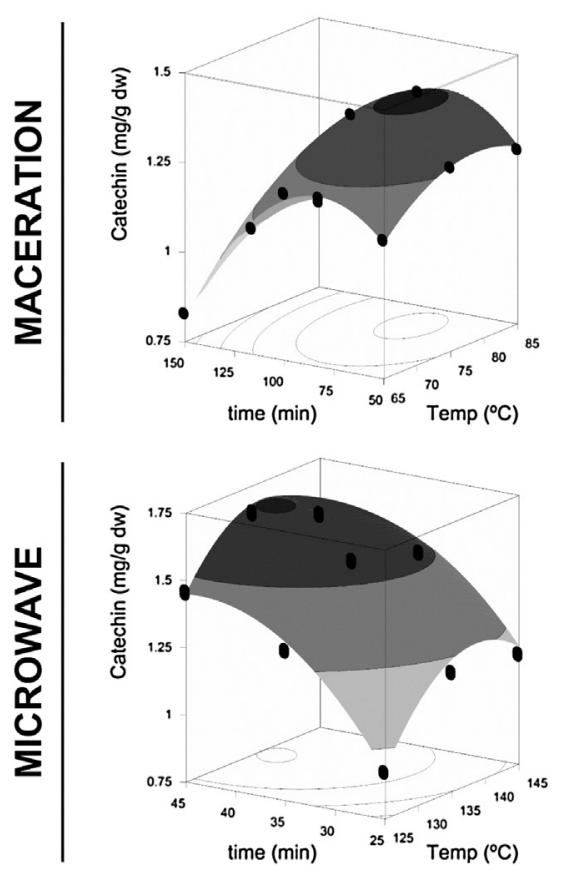

\section{B: INDIVIDUAL ACTION}
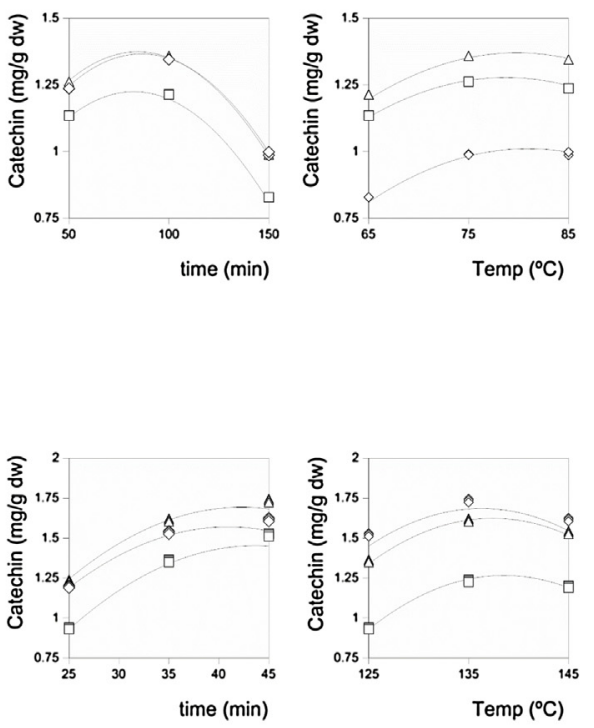
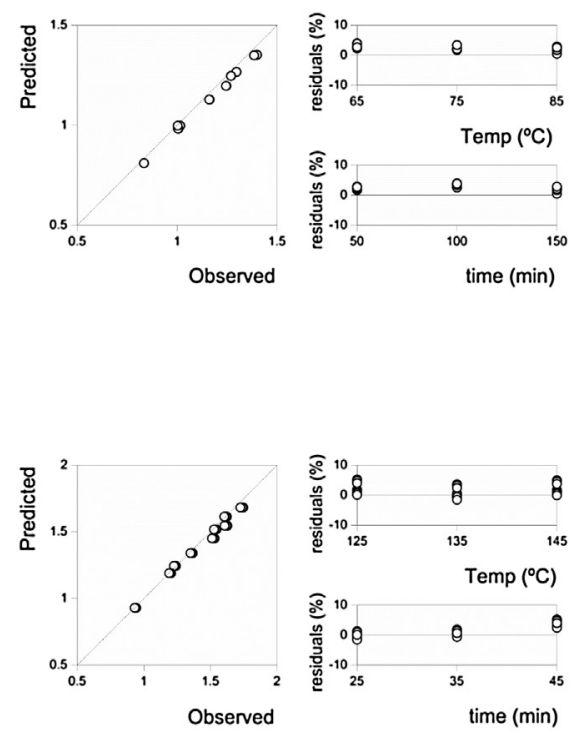

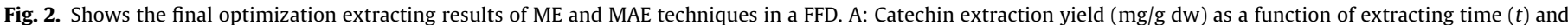

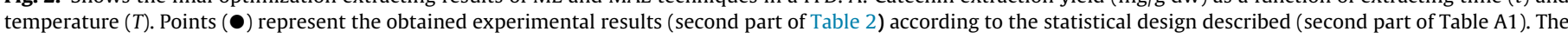

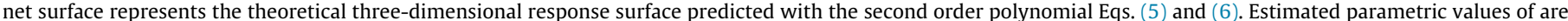

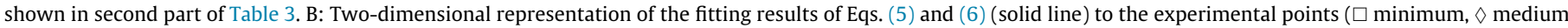

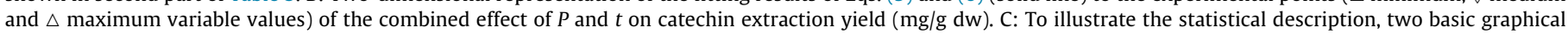
criteria are used: the ability to simulate the changes of the response and the residual distribution as a function of each of the variables.

\subsection{Extraction techniques comparison, numerical optimal} conditions that maximize the extraction, statistical analysis and experimental verification of predictive models

ME, MAE and UAE extraction techniques have been optimized and compared concerning the recovery of catechin rich extracts from A. unedo fruits. These solid/liquid extraction methods have been applied to the extraction of catechin from different source materials (García-Marino et al., 2006; Ghasemzadeh et al., 2014; Meullemiestre et al., 2016; Mieszczakowska-Frąc et al., 2015; Palma and Taylor, 1999; Pingret et al., 2012; Piñeiro et al., 2004).

Although a scientific survey focusing catechin content in different source materials was conducted, pointed out the use of several extraction techniques, as far as we know, there are no references in the literature describing the optimization of catechin extraction from $A$. unedo fruits. Comparing the obtained yields of the present work with the ones available in literature, A. unedo fruits can be considered a suitable source for catechin extraction obtainment (Ananingsih et al., 2013; Gadkari and Balaraman, 2015).

When combining the information produced from the CCCD and FFD approaches, the complete behaviour of each relevant variable influencing catechin extraction is defined in absolute terms. For all techniques the conditions that lead to the optimal values were rechecked in order to ensure the accuracy of the presented results. Fig. 3 shows the summarized individual 2D responses as a function of the defined variables for ME, MAE and UAE extraction techniques to guide the selection of the most favourable conditions. The line represents the variable response pattern when the others are located at the optimal values presented in the third part of Table 4 . The dots $(\odot)$ presented alongside the line highlight the location of the optimal value. Comparing the results of extrac- tion efficiencies among techniques, ME and MAE gave significantly higher values, while UAE extraction generated lower values probably due to degradation flavan-3-ols and particularly catechin as it occurs in other natural compounds (Jacotet-Navarro et al., 2016; Li et al., 2013b). Regarding the extraction time, MAE was the fastest extraction method with $\sim 45$ min while ME needed $\sim 95 \mathrm{~min}$. Considering extraction efficiency, maceration give similar results to MAE. UAE was found not adequate catechin extraction due to its low extraction efficiency.

The performed characterization to optimize catechin extraction yield in ME, MAE and UAE with the RSM provides a strong solution that minimizes the errors with a short number of experimental trials as it has benn demonstrated elsewhere (Roselló-Soto et al., 2015; Wong et al., 2015). The multivariable fitting decreases the number of parameters needed to analyze the response leading to better estimations and reducing their interval of confidence.

The lack-off-fit test used to assess the competence of the models showed that the non-significant parameters of both RSM approaches (Table 3) did not statistically improve the reached solution and, in contrast, all significant parameters were highly consistent $\left(\mathrm{p}<0.01\right.$ ). This was also verified by the achieved high $\mathrm{R}^{2}$ and $\mathrm{R}^{2}$ adj values, indicating the percentage of variability explained by the model (Table 3 ). The distribution of the residuals presented in Fig. 1 and Fig. 2 was arbitrarily around zero and no group of values or autocorrelations were observed. Additionally, the agreement between the experimental and predicted values implies an acceptable explanation of the results obtained by the independent variables used. Therefore, the models developed in Eqs. (2)-(6), either for the $C C C D$ or $F F D$, are completely functional and adequate to be used for prediction and process optimization. 
MACERATION
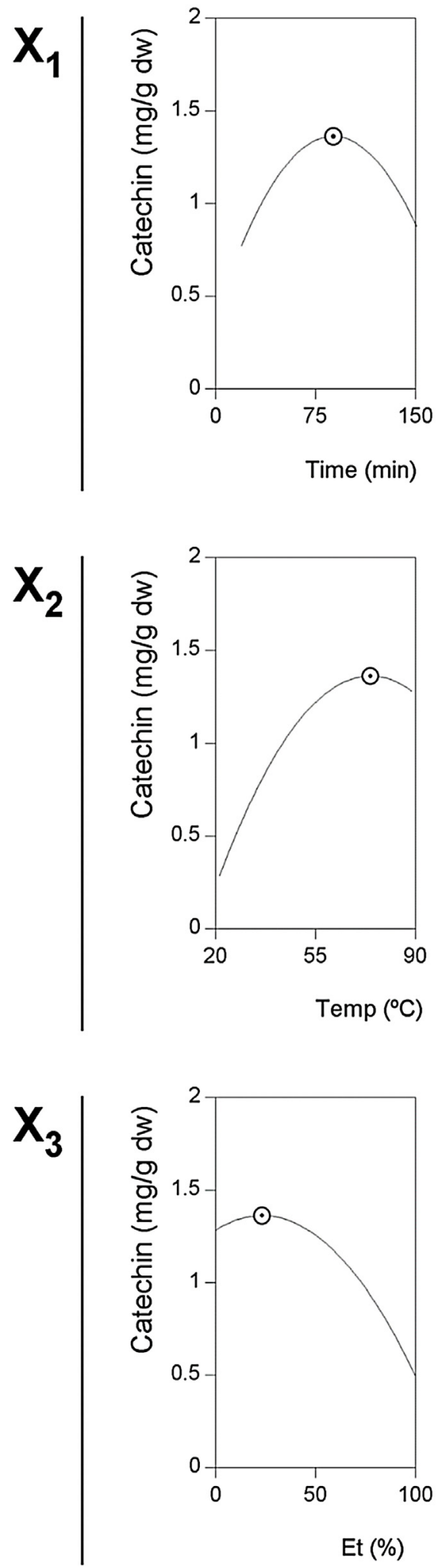

MICROWAVE

ULTRASOUND
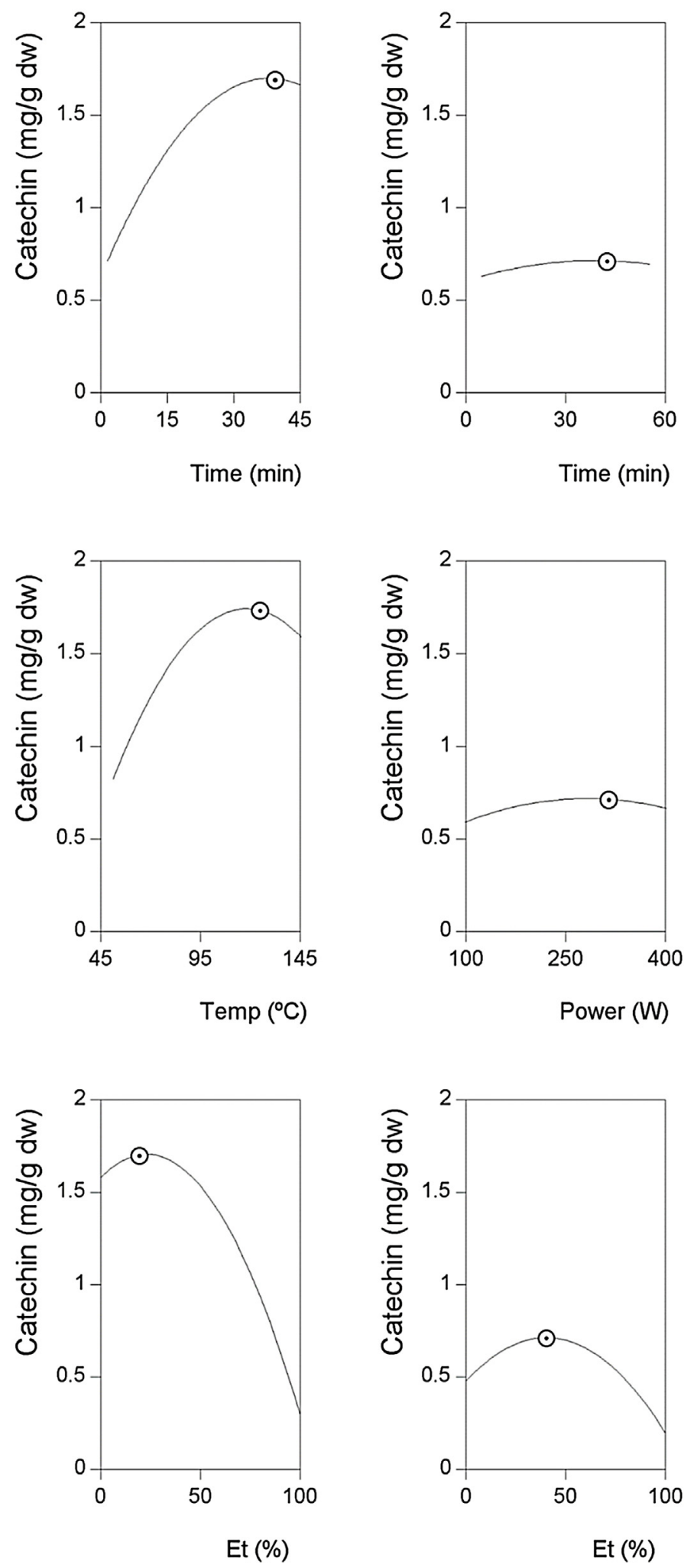

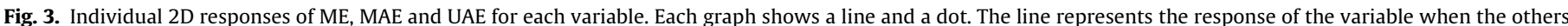

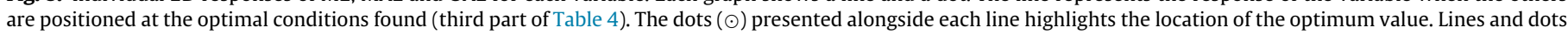
are generated by the theoretical second order polynomial models of Eqs. (2)-(6). Parametric fitting values obtained are presented in Table 3. 


\section{Conclusions}

The extraction process for ME, MAE and UAE was successfully optimized by applying the RSM. The results showed that extraction time, temperature and ethanol content in the used water/ethanol mixtures have significant effects on the catechin extraction yield. ME and MAE were found to be the most effective methods capable of yielding $1.38 \pm 0.1$ and $1.70 \pm 0.3 \mathrm{mg}$ of catechin $/ \mathrm{g} \mathrm{dw}$ at their optimal extraction conditions. MAE was found to be faster and more effective in comparison with other studied techniques, but lower temperature was applied in ME with nearly identical extraction yields, which can be translated in economic benefits. The UAE was the less effective solution in terms of catechin extraction yield.

This work offers an overview through environmental compatible extraction processes, in which the valorisation of $A$. unedo fruits is performed by 'clean' technologies able to integrate a potential industrial sector in a sustainable approach (Boukroufa et al., 2015). The obtained results indicate the viability of using $A$. unedo fruits as a productive source of catechin by any of the assessed techniques and provide evidence of the advantages of maceration, microwave and ultrasound extraction techniques for their industrial production (Achat et al., 2012). In addition, the present work can reinforce the production of $A$. unedo fruits to serve as a source of bioactive compounds to be used as natural additives in functional foods.

\section{Acknowledgements}

The authors thank the Foundation for Science and Technology (FCT, Portugal) and FEDER under Programme PT2020 for financial support to CIMO (UID/AGR/00690/2013) and L. Barros (SFRH/BPD/107855/2015) grant. To POCI-01-0145-FEDER-006984 (LA LSRE-LCM), funded by FEDER, through POCI-COMPETE2020 and FCT. To Xunta de Galicia for financial support for the post-doctoral researcher of M.A. Prieto. B. Albuquerque thanks Celeide Pereira (UTFPR, Brazil) for her master cosupervision.

\section{Appendix A. Supplementary data}

Supplementary data associated with this article can be found, in the online version, at http://dx.doi.org/10.1016/j.indcrop.2016.10. 050.

\section{References}

Achat, S., Tomao, V., Madani, K., Chibane, M., Elmaataoui, M., Dangles, O., Chemat, F., 2012. Direct enrichment of olive oil in oleuropein by ultrasound-assisted maceration at laboratory and pilot plant scale. Ultrason. Sonochem. 19, 777-786.

Alarcão-E-Silva, M.L.C.M.M., Leitão, A.E.B., Azinheira, H.G., Leitão, M.C.A., 2001. The arbutus berry: studies on its color and chemical characteristics at two mature stages. J. Food Compos. Anal. 14, 27-35.

Alonso-Salces, R.M., Korta, E., Barranco, A., Berrueta, L.A., Gallo, B., Vicente, F., 2001. Pressurized liquid extraction for the determination of polyphenols in apple. J. Chromatogr. A 933, 37-43.

Ananingsih, V.K., Sharma, A., Zhou, W., 2013. Green tea catechins during food processing and storage: a review on stability and detection. Food Res. Int. 50, 469-479.

Aron, P.M., Kennedy, J.A., 2008. Flavan-3-ols: nature, occurrence and biological activity. Mol. Nutr. Food Res. 52, 79-104.

Bezerra, M.A., Santelli, R.E., Oliveira, E.P., Villar, L.S., Escaleira, E.A., 2008. Response surface methodology (RSM) as a tool for optimization in analytical chemistry. Talanta 76, 965-977.

Boukroufa, M., Boutekedjiret, C., Petigny, L., Rakotomanomana, N., Chemat, F., 2015. Bio-refinery of orange peels waste: a new concept based on integrated green and solvent free extraction processes using ultrasound and microwave techniques to obtain essential oil, polyphenols and pectin. Ultrason. Sonochem. 24, 72-79.

Box, G., Hunter, J., 1957. Multi-factor experimental designs for exploring response surfaces. Ann. Math. Stat. 28, 195-241.

Box, G.E.P., Hunter, J.S., William Hunter, G., 2005. Statistics for Experimenters: Design, Innovation and Discovery, 2nd ed. Wiley.
Chemat, F., Rombaut, N., Sicaire, A., Meullemiestre, A., Abert-vian, M., 2017. Ultrasonics sonochemistry ultrasound assisted extraction of food and natural products. Mechanisms techniques, combinations, protocols and applications. A review. Ultrason. - Sonochem. 34, 540-560.

Chen, Z., Zhang, L., Chen, G., 2008. Microwave-assisted extraction followed by capillary electrophoresis-amperometric detection for the determination of antioxidant constituents in Folium Eriobotryae. J. Chromatogr. A 1193, $178-181$

Comuzzi, C., Polese, P., Melchior, A., Portanova, R., Tolazzi, M., 2003. SOLVERSTAT: a new utility for multipurpose analysis. An application to the investigation of dioxygenated Co (II) complex formation in dimethylsulfoxide solution. Talanta 59, 67-80.

Dai, J., Mumper, R.J., 2010. Plant phenolics: extraction, analysis and their antioxidant and anticancer properties. Molecules 15, 7313-7352.

Ferreira, S.L.C., Bruns, R.E., Ferreira, H.S., Matos, G.D., David, J.M., Brandão, G.C., da Silva, E.G.P., Portugal, L.A., dos Reis, P.S., Souza, A.S., dos Santos, W.N.L., 2007. Box-Behnken design: an alternative for the optimization of analytical methods. Anal. Chim. Acta 597, 179-186.

Fortalezas, S., Tavares, L., Pimpão, R., Tyagi, M., Pontes, V., Alves, P.M., Mcdougall, G., Stewart, D., Ferreira, R.B., Santos, C.N., 2010. Antioxidant properties and neuroprotective capacity of strawberry tree fruit (Arbutus unedo). Nutrients 2 , 214-229

Gadkari, P.V., Balaraman, M., 2015. Catechins: sources, extraction and encapsulation: a review. Food Bioprod. Process. 93, 122-138.

Galanakis, C.M., 2012. Recovery of high added-value components from food wastes: conventional, emerging technologies and commercialized applications. Trends Food Sci. Technol. 28, 68-87.

Galanakis, C.M., 2013. Emerging technologies for the production of nutraceuticals from agricultural by-products: a viewpoint of opportunities and challenges. Food Bioprod. Process. 91, 575-579.

Garavand, F., Madadlou, A., Moini, S., 2015. Determination of phenolic profile and antioxidant activity of pistachio hull using HPLC-DAD-ESI-MS as affected by ultrasound and microwave. Int. J. Food Prop. 2, 23-30.

García-Marino, M., Rivas-Gonzalo, J.C., Ibñez, E., García-Moreno, C., 2006. Recovery of catechins and proanthocyanidins from winery by-products using subcritical water extraction. Anal. Chim. Acta 563, 44-50.

Ghasemzadeh, A., Jaafar, H.Z.E., Karimi, E., Rahmat, A., 2014. Optimization of ultrasound-assisted extraction of flavonoid compounds and their pharmaceutical activity from curry leaf (Murraya koenigii L.) using response surface methodology. BMC Complement. Altern. Med. 14, 1-10.

Guimarães, R., Barros, L., Dueñas, M., Carvalho, A.M., Queiroz, M.J.R.P., Santos-Buelga, C., Ferreira, I.C.F.R., 2013. Characterisation of phenolic compounds in wild fruits from Northeastern Portugal. Food Chem. 141, $3721-3730$.

Heleno, S.A., Diz, P., Prieto, M.A., Barros, L., Rodrigues, A., Barreiro, M.F., Ferreira, I.C.F.R., 2016. Optimization of ultrasound-assisted extraction to obtain mycosterols from Agaricus bisporus L. by response surface methodology and comparison with conventional Soxhlet extraction. Food Chem. 197, 1054-1063, Pt B.

Herrera, M.C., Luque De Castro, M.D., 2004. Ultrasound-assisted extraction for the analysis of phenolic compounds in strawberries. Anal. Bioanal. Chem. 379, 1106-1112.

Higdon, J.V., Frei, B., 2003. Tea catechins and polyphenols: health effects, metabolism, and antioxidant functions. Crit. Rev. Food Sci. Nutr. 43, 89-143.

Hirasawa, M., Takada, K., 2004. Multiple effects of green tea catechin on the antifungal activity of antimycotics against Candida albicans. J. Antimicrob. Chemother. 53, 225-229.

Ince, A.E., Şahin, S., Şümnü, S.G., 2013. Extraction of phenolic compounds from melissa using microwave and ultrasound. Turk. J. Agric. For. 37, 69-75.

Jacotet-Navarro, M., Rombaut, N., Deslis, S., Fabiano-Tixier, A.-S., Pierre, F.-X., Bily, A., Chemat, F., 2016. Towards a dry bio-refinery without solvents or added water using microwaves and ultrasound for total valorization of fruit and vegetable by-products. Green Chem. 18, 3106-3115.

Kalil, S., Maugeri, F., 2000. Response surface analysis and simulation as a tool for bioprocess design and optimization. Process Biochem. 35, 539-550.

Kemmer, G., Keller, S., 2010. Nonlinear least-squares data fitting in Exce spreadsheets. Nat. Protoc. 5, 267-281.

Li, Y., Fabiano-Tixier, A.-S., Vian, M., Chem, F., 2013a. Solvent-free microwave extraction of bioactive compounds provides a tool for green analytical chemistry. Trends Anal. Chem. 47, 1-11.

Li, Y., Fabiano-Tixier, A.S., Tomao, V., Cravotto, G., Chemat, F., 2013b. Green ultrasound-assisted extraction of carotenoids based on the bio-refinery concept using sunflower oil as an alternative solvent. Ultrason. Sonochem. 20, $12-18$.

Lotito, S.B., Fraga, C.G., 1998. (+)-Catechin prevents human plasma oxidation. Free Radic. Biol. Med. 24, 435-441.

Meullemiestre, A., Petitcolas, E., Maache-Rezzoug, Z., Chemat, F., Rezzoug, S.A., 2016. Impact of ultrasound on solid-liquid extraction of phenolic compounds from maritime pine sawdust waste. Kinetics, optimization and large scale experiments. Ultrason. Sonochem. 28, 230-239.

Mieszczakowska-Frac, M., Dyki, B., Konopacka, D., 2015. Effects of ultrasound on polyphenol retention in apples after the application of predrying treatments in liquid medium. Food Bioprocess Technol. 9, 1-10.

Murado, M.A., Prieto, M.A., 2013. Dose-response analysis in the joint action of two effectors a new approach to simulation, identification and modelling of some basic interactions. PLoS One 8, e61391. 
Nagao, T., Meguro, S., Hase, T., Otsuka, K., Komikado, M., Tokimitsu, I., Yamamoto, T., Yamamoto, K., 2009. A catechin-rich beverage improves obesity and blood glucose control in patients with type 2 diabetes. Obesity (Silver Spring) 17, 310-317.

Pabuçcuoğlu, A., Kıvçak, B., Baş, M., Mert, T., 2003. Antioxidant activity of Arbutus unedo leaves. Fitoterapia 74, 597-599.

Pallauf, K., Rivas-Gonzalo, J.C., del Castillo, M.D., Cano, M.P., de Pascual-Teresa, S., 2008. Characterization of the antioxidant composition of strawberry tree (Arbutus unedo L.) fruits. J. Food Compos. Anal. 21, 273-281.

Palma, M., Taylor, L.T., 1999. Extraction of polyphenolic compounds from grape seeds with near critical carbon dioxide. J. Chromatogr. A 849, 117-124.

Pawlowska, A.M., De Leo, M., Braca, A., 2006. Phenolics of Arbutus unedo L. (Ericaceae) fruits: identification of anthocyanins and gallic acid derivatives. J. Agric. Food Chem. 54, 10234-10238.

Piñeiro, Z., Palma, M., Barroso, C.G., 2004. Determination of catechins by means of extraction with pressurized liquids. J. Chromatogr. A 1026, 19-23.

Pinela, J., Prieto, M.A., Barreiro, M.F., Carvalho, A.M., Oliveira, M.B.P.P., Vázquez, J.A., Ferreira, I.C.F.R., 2016. Optimization of microwave-assisted extraction of hydrophilic and lipophilic antioxidants from a surplus tomato crop by response surface methodology. Food Bioprod. Process. 98, 283-298.

Pingret, D., Fabiano-Tixier, A.-S., Bourvellec, C., Le Renard, C.M.G.C., Chemat, F., 2012. Lab and pilot-scale ultrasound-assisted water extraction of polyphenols from apple pomace. J. Food Eng. 111, 73-81.

Prikler, S., 2009. Advanced Excel for scientific data analysis, 2nd ed. ed. Robert de Levie Ed.

Proestos, C., Komaitis, M., 2008. Application of microwave-assisted extraction to the fast extraction of plant phenolic compounds. LWT - Food Sci. Technol. 41, $652-659$
Roselló-Soto, E., Galanakis, C.M., Brnčić, M., Orlien, V., Trujillo, F.J., Mawson, R., Knoerzer, K., Tiwari, B.K., Barba, F.J., 2015. Clean recovery of antioxidant compounds from plant foods, by-products and algae assisted by ultrasounds processing. Modeling approaches to optimize processing conditions. Trends Food Sci. Technol. 42, 134-149.

Ruiz-Rodríguez, B.-M., Morales, P., Fernández-Ruiz, V., Sánchez-Mata, M.-C., Cámara, M., Díez-Marqués, C., Pardo-de-Santayana, M., Molina, M., Tardío, J., 2011. Valorization of wild strawberry-tree fruits (Arbutus unedo L.) through nutritional assessment and natural production data. Food Res. Int. 44, 1244-1253.

Vuong, Q.V., Golding, J.B., Nguyen, M., Roach, P.D., 2010. Extraction and isolation of catechins from tea. J. Sep. Sci. 33, 3415-3428.

Vuong, Q.V., Golding, J.B., Stathopoulos, C.E., Nguyen, M.H., Roach, P.D., 2011. Optimizing conditions for the extraction of catechins from green tea using hot water. J. Sep. Sci. 34, 3099-3106.

Wong, W.H., Lee, W.X., Ramanan, R.N., Tee, L.H., Kong, K.W., Galanakis, C.M., Sun, J., Prasad, K.N., 2015. Two level half factorial design for the extraction of phenolics, flavonoids and antioxidants recovery from palm kernel by-product. Ind. Crops Prod. 63, 238-248.

Zhang, Z., Lv, G., Pan, H., Fan, L., 2012. Optimisation of the microwave-assisted extraction process for six phenolic compounds in Agaricus blazei murrill. Int. J. Food Sci. Technol. 47, 24-31.

Ziyyat, A., Mekhfi, H., Bnouham, M., Tahri, A., Legssyer, A., Hoerter, J., Fischmeister, R., 2002. Arbutus unedo induces endothelium-dependent relaxation of the isolated rat aorta. Phyther. Res. 16, 572-575. 